\title{
Formulation and Evaluation of Losartan Potassium Osmotic Controlled Matrix Tablets
}

\author{
Vidyadhara Suryadevara*, Sasidhar Reddyvalam Lankapalli, Uma Maheswar Rao Vejella, Sundeep \\ Mupparaju and Showri babu Chava
}

Chebrolu Hanumaiah Institute of Pharmaceutical Sciences, Chandarmoulipuram , Chowdavaram, Guntur-522019, A.P. INDIA.

\begin{abstract}
Osmotically controlled oral drug delivery systems utilize osmotic pressure as energy source for the controlled delivery of drugs, independent of $\mathrm{pH}$ and hydrodynamic conditions of gastro intestinal tract (GIT). The present study was aimed to develop osmotic controlled extended release formulations of Losartan potassium an angiotensin II receptor antagonist with anti-hypertensive activity. Losartan potassium matrix tablets were prepared by direct compression process using HPMC K $15 \mathrm{M}$ as polymeric material and mannitol as osmogen at varied concentrations. The matrix tablets were further coated with different compositions of ethylcellulose7cps and PEG-4000 by pan coating method. Physical parameters such as weight uniformity, drug content, hardness and friability were evaluated for uncoated tablets and were found to be within I.P limits. The coating thickness and percentage of coating applied for various tablets were also evaluated. The optimized coated tablets were further subjected to micro drilling on the upper face to get $0.5 \mu \mathrm{m}$ orifice diameter. All the tablets were further subjected to dissolution studies by using USP apparatus II with distilled water as medium. These studies indicated that all the tablets were found to release the drug up to 12 hours, while coated tablets with orifice found to release the drug at zero order rate, which was in good agreement with peppas $\mathrm{n}$ values $>0.9$.
\end{abstract}

Key words: Losartan potassium, osmotic pressure, micro drilling, controlled release.

\section{INTRODUCTION}

The oral route for drug delivery is the most popular, desirable and most preferred method for administrating therapeutically active agents for systemic effects, because it is a natural, convenient and cost effective to manufacturing process. Oral route is the most commonly used route for drug administration. Although different routes of administration are used for the delivery of drugs, oral route remain the preferred mode. Even for sustained release systems the oral route of administration has been investigated the most, because of flexibility in designing dosage forms. Present controlled release drug delivery systems are for a maximum of 12 hours clinical effectiveness. Such systems are primarily used for the drugs with short elimination half life.

Osmotically controlled oral drug delivery systems (OCODDS) utilize osmotic pres- sure as the energy source for the controlled delivery of drugs. These systems are suitable for delivery of drugs having moderate water solubility. ${ }^{1}$ Drug release from these systems is independent of $\mathrm{pH}$ and hydrodynamic conditions of the gastro-intestinal tract $(\mathrm{GIT})^{2}$ to the large extent and release characteristics can be easily adjusted by optimizing the parameters of delivery system. ${ }^{3,4}$ Osmotic devices are most promising strategy based systems for controlled drug delivery. They are among the most reliable controlled drug delivery systems and could be employed as oral drug delivery systems or implantable devices. Osmosis is an aristocratic bio phenomenon, which is exploited for development of delivery systems with every desirable property of an ideal controlled drug delivery system. Osmotic system utilizes the principles of osmotic pressure for delivery of drug. ${ }^{5}$
Submission Date : 30-04-13 Revision Date : :22-09-14 Accepted Date : :06-11-14

DOI: $10.5530 /$ ijper.48.4s.3 Correspondence Address Dr. S. Vidyadhara Professor and Principal, Chebrolu Hanumaiah Institute of Pharmaceutical Sciences, Chandarmoulipuram, Chowdavaram , Guntur-522019 A.P, INDIA

Email: svidyadhara@gmail. com

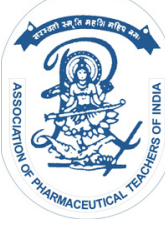

www.ijper.org 
Losartan Potassium is an angiotensin II receptor antagonist with anti hypertensive activity. It belongs to class 1 of Biopharmaceutical Classification System (BCS). It is readily absorbed from the GI tract following oral administration but the bioavailability is about 33\% due to substantial first-pass metabolism. Peak plasma concentration occurs at about $1 \mathrm{hr}$ after an oral dose and has short terminal elimination halflife is about 1.5 to $2 \mathrm{hrs}$ respectively, thereby requiring two to three times daily dosing in large number of patients, which often leads to non-compliance. ${ }^{6}$ Thus, there is a strong clinical need and market potential for a dosage form that will deliver Losartan Potassium in a controlled manner to a patient needing this therapy, thereby resulting in a better patient compliance.

The present study was aimed towards the development of extended release formulations of Losartan potassium based on osmotic technology. In this study, osmotic drug delivery matrix tablets of Losartan potassium were developed. The core tablets of Losartan Potassium consisted of drug along with an osmotic agent (mannitol) and swellable polymer hydroxy propyl methylcellulose ${ }^{7-10}$ (methocel). The core tablets were coated with ethyl Cellulose 7 $\mathrm{cps}^{11,12}$ and PEG-4000. After coating, the optimized coated tablets were further subjected to micro drilling on the upper face to get $0.5 \mu \mathrm{m}$ orifice diameter that release the drug at controlled manner. This study was intended to evaluate the influence of formulation variables like levels of swellable polymer, amount of mannitol concentration and coating solution ratios of semi permeable membrane (SPM) on the drug release from the tablet formulations.

\section{MATERIALS AND METHODS}

\section{Materials}

Losartan Potassium was obtained as gift sample from M/S AUROBINDO Pharma Ltd, Hyderabad. Hydroxy propyl methyl cellulose (Methocel/HPMCK ${ }_{15} \mathrm{M}$ ) was obtained as gift sample from M/S Colorcon Asia Pvt. Ltd, Mumbai. Microcrystalline Cellulose (Tabulose) and Mannitol was obtained as Gift Sample from M/S Matrix Pharma Ltd, Hyderabad. Talc and magnesium stearate were obtained commercially from Loba Chemie Pvt. Ltd, Mumbai. Ethyl cellulose-7cps was obtained commercially from S.D.Fine Chem. Ltd, Mumbai. Poly Ethylene Glycol-4000 was obtained as gift sample from Sisco Research Laboratories Pvt. Ltd, Mumbai.

\section{PREPARATION OF OSMOTIC TABLETS}

\section{Preparation of Core Tablets}

The osmotic core tablets of Losartan potassium were prepared by direct compression process. ${ }^{13,14}$ Losartan Potassium was blended with HPMC $\mathrm{K}_{15} \mathrm{M}$ in a double cone blender for $10 \mathrm{~min}$. The mixture was passed through \#30 mesh sieve, and osmotic agent (mannitol), MCC were added in geometric dilution and blending is continued for additional $10 \mathrm{~min}$. To this mixture talc and magnesium stearate which were passed through \#60 mesh sieve were added and blending is continued for additional $5 \mathrm{~min}$. The blend was then compressed into tablets using Clit 10 station mini press. The same procedure was employed for preparing different batches of tablets with varying mannitol concentration. To minimize processing variables all batches of tablets were compressed under identical conditions. The compressed core tablets were further evaluated for their physical parameters such as weight uniformity, friability, Hardness and Drug content. The composition of different tablet formulations of Losartan Potassium were given in (Table 1).

\section{Coating and Drilling}

Core tablets of Losartan Potassium were coated in a conventional laboratory coating pan (Scientific instrument, New Delhi, India) fitted with three baffles placed at angle of $120^{\circ}$ having outer diameter of $10 \mathrm{~cm}$. The components of coating solution were added to solvent

\section{Table 1: Formula for Different Batches of Optimized Core Tablet Formulation of Losartan Potassium with Vary- ing Mannitol Concentration.}

\begin{tabular}{|c|c|c|c|c|c|c|c|c|c|}
\hline \multirow{2}{*}{$\begin{array}{l}\text { INGREDIENTS } \\
\text { (mg/tablet) }\end{array}$} & \multicolumn{9}{|c|}{ FORMULATIONS } \\
\hline & LP1 & LP2 & LP3 & LP4 & LP5 & LP6 & LP7 & LP8 & LP9 \\
\hline Losartan potassium & 90 & 90 & 90 & 90 & 90 & 90 & 90 & 90 & 90 \\
\hline HPMCK15 M & 45 & 45 & 45 & 45 & 45 & 45 & 45 & 45 & 45 \\
\hline Mannitol & 30 & 40 & 50 & 60 & 70 & 80 & 90 & 100 & 110 \\
\hline MCC & 180 & 170 & 160 & 150 & 140 & 130 & 120 & 110 & 100 \\
\hline Talc & 3 & 3 & 3 & 3 & 3 & 3 & 3 & 3 & 3 \\
\hline Magnesium stearate & 2 & 2 & 2 & 2 & 2 & 2 & 2 & 2 & 2 \\
\hline Total weight(mg) & 350 & 350 & 350 & 350 & 350 & 350 & 350 & 350 & 350 \\
\hline
\end{tabular}


Table 2: Coating composition

\begin{tabular}{|l|c|c|c|c|c|}
\hline \multirow{2}{*}{ INGREDIENTS } & \multicolumn{5}{|c|}{ COATING CODE } \\
\cline { 2 - 6 } & $\mathbf{L P}_{5 \mathrm{~A}}$ & $\mathbf{L P}_{5 \mathrm{~B}}$ & $\mathbf{L P}_{5 \mathrm{C}}$ & $\mathbf{L P}_{5 \mathrm{D}}$ & $\mathbf{L P}_{5 \mathrm{5E}}$ \\
\hline $\begin{array}{l}\text { Ethyl cellulose } \\
\text { 7cps (gm) }\end{array}$ & 2 & 1.6 & 1.4 & 1.2 & 1 \\
\hline PEG-4000 (gm) & - & 0.4 & 0.6 & 0.8 & 1 \\
\hline $\begin{array}{l}\text { Dichloro } \\
\text { methane (ml) }\end{array}$ & 20 & 20 & 20 & 20 & 20 \\
\hline
\end{tabular}

mixture in sequential manner. The component added first was allowed to dissolve before next component was added. Coating process was done on a batch of 100 tablets. Pan speed was maintained at $50 \mathrm{rpm}$ and hot air inlet temperature was kept at $38-42^{\circ} \mathrm{C}$. The manual coating procedure based on intermittent spraying and coating procedure was used with spray rate of $4-5 \mathrm{ml} / \mathrm{min}$. Coat weight and thickness were controlled by the volume of coating solution consumed in coating process . Coating was continued until desired coat thickness was obtained on the core tablets. In all cases coated tablets were dried at $50^{\circ} \mathrm{C}$ for $6 \mathrm{hrs}$ before further evaluation. The composition of coating solutions used for coating of core tablets was given in (Table 2). An appropriate size orifice $(0.5 \mu \mathrm{m})$ is made on one face of all coated tablets using micro drill. (Kamlesh Engineers, Udaipur, India).

\section{Evaluation of Physical Parameters}

Before compression process, the powder blends were evaluated for flow properties such as angle of repose and Carr's index. ${ }^{15}$ After the compression of matrix tablets they were further evaluated for physical parameters such as weight uniformity, drug content, hardness and friability. ${ }^{16}$ The physical parameters evaluated were given in (Table 3).

\section{Drug content uniformity}

Osmotic tablet of Losartan Potassium from a batch was taken at random and was crushed to a fine powder. The powdered material was transferred into a $100 \mathrm{ml}$ volumetric flask and $70 \mathrm{ml}$ of distilled water was added to it. It was shaken occasionally for about 30 minutes and the volume was made up to $100 \mathrm{ml}$ by adding distilled water. About $10 \mathrm{ml}$ of the solution from the volumetric flask was taken and centrifuged. The supernatant solution from the centrifuge tube was collected and again filtered by using Millipore filter ${ }^{16}$ Then the filtrate was subsequently diluted and the absorbance was measured at $250 \mathrm{~nm}$. This test was repeated six times $(\mathrm{N}=6)$ for each batch of tablets. The amounts of Losartan Potassium estimated from different batches were given in (Table 3).

\section{In vitro dissolution studies}

Dissolution studies for core formulations and coated formulations for Losartan Potassium controlled release osmotic tablets were performed on a calibrated 8 station (LABINDIA) dissolution apparatus equipped with paddles employing $900 \mathrm{ml}$ of distilled water for 12 hour's. The paddles were operated to rotate at $100 \mathrm{rpm}$ and the temperature of the medium was maintained at $37 \pm 1^{\circ} \mathrm{C}$ throughout the studies. Dissolution samples were withdrawn at regular intervals up to $12 \mathrm{hrs}$ and replaced with equal volume to maintain the constant volume of the dissolution medium throughout the studies. The drug content in the samples was determined by measuring

\begin{tabular}{|l|c|c|c|c|}
\hline \multicolumn{1}{|c|}{ Formulations } & Weight Uniformity(mg) & Hardness (Kg/cm2) & Fraibility(\%) & $\begin{array}{c}\text { Drug Content(mg/ } \\
\text { tablet) }\end{array}$ \\
\hline LP1 & $349 \pm 2.0$ & $5.8 \pm 0.2$ & 0.16 & $89.6 \pm 0.4$ \\
\hline LP2 & $347 \pm 2.0$ & $5.8 \pm 0.2$ & 0.12 & $89.1 \pm 0.5$ \\
\hline LP3 & $348 \pm 5.0$ & $5.8 \pm 0.2$ & 0.17 & $89.2 \pm 0.4$ \\
\hline LP4 & $348 \pm 2.0$ & $6.2 \pm 0.2$ & 0.16 & $89.5 \pm 0.2$ \\
\hline LP5 & $346 \pm 2.0$ & $6.2 \pm 0.2$ & 0.15 & $89.2 \pm 0.4$ \\
\hline LP6 & $346 \pm 3.0$ & $5.6 \pm 0.2$ & 0.12 & $89.3 \pm 0.3$ \\
\hline LP7 & $347 \pm 4.0$ & $5.6 \pm 0.2$ & 0.14 & $89.1 \pm 0.2$ \\
\hline LP8 & $348 \pm 3.0$ & $5.6 \pm 0.2$ & 0.13 & $90.2 \pm 0.5$ \\
\hline LP9 & $351 \pm 2.0$ & $5.6 \pm 0.2$ & 0.15 & $89.1 \pm 0.6$ \\
\hline LP5A & $348 \pm 3.0$ & $6.0 \pm 0.2$ & 0.12 & $89.4 \pm 0.1$ \\
\hline LP5B & $346 \pm 2.0$ & $6.0 \pm 0.2$ & 0.13 & $88.1 \pm 0.4$ \\
\hline LP5C & $345 \pm 2.0$ & $6.4 \pm 0.3$ & 0.16 & $90.2 \pm 0.3$ \\
\hline LP5D & $349 \pm 2.0$ & $6.4 \pm 0.3$ & 0.18 & $90.4 \pm 0.2$ \\
\hline LP5E & $348 \pm 3.0$ & $6.4 \pm 0.3$ & 0.14 & $89.5 \pm 0.3$ \\
\hline
\end{tabular}


Table 4 : Evaluation of Dissolution Parameters for LP1-LP9 Tablet Formulations without Pore.

\begin{tabular}{|c|c|c|c|c|c|c|c|c|}
\hline \multirow[t]{2}{*}{ Formulation } & \multicolumn{2}{|c|}{$\begin{array}{c}\text { Zero Order Rate } \\
\text { Constant }\end{array}$} & \multicolumn{2}{|c|}{ First Order Rate Constant } & \multicolumn{2}{|c|}{ Higuchi's Constants } & \multicolumn{2}{|c|}{ Peppa's Constant } \\
\hline & $\begin{array}{c}\mathrm{K} \\
(\mathrm{mg})\end{array}$ & $\mathbf{R}^{2}$ & $\begin{array}{c}\mathrm{K} \\
\left(\mathrm{hr} r^{-1}\right)\end{array}$ & $\mathbf{R}^{2}$ & $\begin{array}{c}\mathrm{K} \\
\left(\mathrm{mg}^{1 / 2}\right)\end{array}$ & $\mathbf{R}^{2}$ & $\mathbf{N}$ & $\mathbf{R}^{2}$ \\
\hline LP1 & 2.76 & 0.8843 & 0.034 & 0.9917 & 10.39 & 0.9943 & 0.7261 & 0.9966 \\
\hline LP2 & 3.55 & 0.8844 & 0.047 & 0.9936 & 13.37 & 0.9942 & 0.7258 & 0.9966 \\
\hline LP3 & 4.18 & 0.8889 & 0.059 & 0.9963 & 15.60 & 0.9923 & 0.7020 & 0.9962 \\
\hline LP4 & 6.26 & 0.8779 & 0.1274 & 0.9922 & 22.64 & 0.9945 & 0.5926 & 0.9953 \\
\hline LP5 & 7.65 & 0.8824 & 0.2653 & 0.9411 & 28.07 & 0.9923 & 0.6248 & 0.9849 \\
\hline LP6 & 7.07 & 0.8923 & 0.1557 & 0.9871 & 27.13 & 0.9967 & 0.7904 & 0.9997 \\
\hline LP7 & 7.46 & 0.8939 & 0.2012 & 0.9555 & 28.39 & 0.9937 & 0.7604 & 0.9996 \\
\hline LP8 & 7.97 & 0.8905 & 0.288 & 0.9334 & 30.22 & 0.9946 & 0.7535 & 0.9976 \\
\hline LP9 & 7.97 & 0.8845 & 0.2913 & 0.9462 & 29.88 & 0.9972 & 0.7113 & 0.9977 \\
\hline
\end{tabular}

Table 5: Evaluation of Dissolution Parameters for LP5C Tablet Formulation with

\begin{tabular}{|c|c|l|l|l|l|l|l|l|l|}
\hline \multirow{2}{*}{ Formulation } & \multicolumn{10}{c|}{$\begin{array}{c}\text { Zero Order } \\
\text { Rate Constant }\end{array}$} & \multicolumn{2}{c|}{$\begin{array}{c}\text { First Order } \\
\text { Rate Constant }\end{array}$} & \multicolumn{2}{c|}{$\begin{array}{c}\text { Higuchi's } \\
\text { Constants }\end{array}$} & \multicolumn{2}{|c|}{$\begin{array}{c}\text { Peppa's } \\
\text { Constan }\end{array}$} \\
\cline { 2 - 10 } & $\mathrm{K}(\mathrm{mg})$ & $\mathrm{R}^{2}$ & $\begin{array}{l}\mathrm{K} \\
\left(\mathrm{hr}^{-1}\right)\end{array}$ & $\mathrm{R}^{2}$ & $\begin{array}{l}\mathrm{K} \\
\left(\mathrm{mg}^{1 / 2}\right)\end{array}$ & $\mathrm{R}^{2}$ & $\mathrm{~N}$ & $\mathrm{R}^{2}$ \\
\hline LP5C & 7.358 & 0.9969 & 0.4094 & 0.9426 & 34.88 & 0.9883 & 0.9125 & 0.9938 \\
\hline
\end{tabular}

\begin{tabular}{|c|c|c|c|c|c|}
\hline Formulations & Storage Condition & $\begin{array}{l}\text { Weight Uniformity } \\
(\mathrm{mg})\end{array}$ & Hardness (Kg/cm2) & Friability (\%) & $\begin{array}{c}\text { Drug Content (mg/ } \\
\text { tablet) }\end{array}$ \\
\hline \multirow[t]{3}{*}{ LP5 } & Before storage & $348 \pm 3$ & $5.8 \pm 0.2$ & 0.12 & $89.5 \pm 0.5$ \\
\hline & $25 \pm 20 \mathrm{C}, 60 \pm 5 \% \mathrm{RH}$ & $348 \pm 3$ & $5.8 \pm 0.2$ & 0.12 & $89.3 \pm 0.5$ \\
\hline & $40 \pm 20 \mathrm{C}, 75 \pm 5 \% \mathrm{RH}$ & $348 \pm 3$ & $5.8 \pm 0.2$ & 0.13 & $89.2 \pm 0.5$ \\
\hline
\end{tabular}

the absorbance at $250 \mathrm{~nm}$ on ELICO double beam UV spectrophotometer after suitable dilution of the samples. ${ }^{17}$ Necessary corrections were made for the loss of drug due to each sampling and plotted the cumulative $\%$ amount of drug released Vs time. (Table 4).

The In vitro dissolution studies were performed 6 times for each batch of formulation as per I.P dissolution acceptance criteria, and the average of 6 values were taken for studies. $(n=6)$.

\section{Characterization of osmotic tablets}

Selected formulations were subjected to IR and DSC studies to identify any possible interactions between drug and excipients. The surface characteristics of the tablets were characterized by SEM analysis.(Table $5,6)$.

\section{Accelerated stability studies}

The formulation which showed good in vitro performance was subjected to accelerated stability studies. These studies were carried out by investigating the effect of temperature on the physical properties of tablets and drug release from matrix tablets containing Losartan potassium.

\section{RESULTS AND DISCUSSION}

Extended release formulation of Losartan Potassium osmotic tablets were developed and evaluated. Extended release Osmotic tablets of Losartan Potassium were prepared by direct compression process. Losartan Potassium osmotic tablets were prepared by using HPMCK15M as release rate retardant. All the tablets were evaluated for physical parameters such as weight uniformity, hardness, friability and drug content. Tablets were coated with coating solution containing Ethyl Cellulose and PEG4000. The optimized coated tablets were further subjected to micro drilling on the upper face to get $0.5 \mu \mathrm{m}$ orifice diameter. The composition of various tablets and coating composition were given in (Tables 1 and 2). All the tablets were prepared under identical conditions to minimize the processing variables. Direct compression method was found to be suitable for drug and polymers 
used. The formulations were further evaluated for in vitro drug release. Effect of formulation variables like amount of Mannitol and coating concentration were evaluated. The formulations were further subjected to characterization studies such as DSC, FTIR and SEM analysis.

The flow properties such as angle of repose and Carr's index were evaluated for various powder blends and were found to exhibit good flow properties. The angle of repose values obtained for various powder blends were in the range of 20 to $30^{\circ}$ and the Carr's index values were in the range of 12 to $16 \%$. All the tablet formulations were found to be stable and meeting I.P specified limits for physical parameters evaluated such as weight uniformity, friability and drug content. Weight uniformity of all Osmotic tablet formulations were in the range of $350 \pm 5 \mathrm{mg}$. Hardness of the all Osmotic tablet formulations were in the range of 5.5 to $7.0 \mathrm{Kg} /$ $\mathrm{cm}^{2}$. Friability loss of all tablet formulations were found to be negligible and were in the range of $0.1-0.2 \%$. Drug content was estimated for all Osmotic tablet formulations were highly uniform with less than $1.5 \%$ variation. The physical parameters evaluated for various tablets were given in (Table 3). The percentage weight gain for all the coated tablets were found to be in the range $3 \pm 0.5 \%$. The coating thickness for all the coated tablets was found to be in the range $2.32 \pm 0.5 \mathrm{~mm}$.

All the Osmotic tablet formulations were subjected to in vitro dissolution studies using calibrated 8 station dissolution apparatus equipped with paddle employing $900 \mathrm{ml}$ of diluted water as a medium. Based on the dissolution studies it was observed that tablet formulations LP1 to LP9 prepared by direct compression process were found to release the drug up to $12 \mathrm{hrs}$. The drug release from the matrix tablet formulations was influenced by composition of HPMCK15M and mannitol. As the mannitol concentration was increased, the release of the drug from the matrix tablet was increased. Formulation LP5 containing $20 \%$ of mannitol was found to be ideal concentration for extending the drug release up to 12 hrs at a steady state manner. Hence LP5 formulation was further subjected to coating with semi-permeable polymeric coating composed of various proportions of Ethyl cellulose 7cps and PEG4000 and coating compositions were given (Table 2). The coated tablets were also subjected to dissolution studies by maintaining the similar dissolution conditions for the uncoated tablets. (Figure 1-7).

All the coated tablets were found to extend the drug release more than $12 \mathrm{hrs}$. The drug releases from the coated tablets were influenced by composition of Ethyl cellulose. As the ethyl cellulose composition is high, the formulations LP5 A, B and C were extended the drug release more than 12 hours. Formulations LP5 D and E the drug release is extended upto12 hours, since the composition of Ethyl cellulose is decreased than compared to the above formulations. As the composition of PEG 4000 is increased in formulations LP5 C, D and E the channel formulation in semi-permeable membrane is gradually increased and hence the rate of drug release is increased. Among the coated formulations LP5 C having 7:3 ratio of Ethyl cellulose and PEG 4000 coating composition was found to release drug at a steady state manner. Hence LP5C was further subjected to micro-drilling upon the coating surface. The micro orifice having the approximate pore size of $0.5 \mu \mathrm{m}$ is made on the upper face of the LP5Cformulationby using micro driller. Then this tablet was also subjected to in vitro dissolution studies. The results revealed that LP5C formulation with micro orifice was exhibited linear drug release over a period of 12 hours. Based on the dissolution data various dissolution parameters such as zero order, first order, higuchi constant and peppas constant were evaluated for all the tablet formulations along with LP5C having micro orifice. Formulation LP5C with micro-orifice exhibited zero order drug release profile with release rate constant value of $7.538 \mathrm{mg} / \mathrm{hr}$ and the correlation coefficient value obtained was 0.9969 . The release exponent ( $\mathrm{n}$ value) obtained for the formulation LP5C was 0.9 which indicates that the mechanism of drug release follows zero order which is achieved by drug diffusion from the micro orifice. The higuchi values for the formulation were linear with a $\mathrm{R}^{2}$ value of 0.986 .

The spectra of Losartan Potassium exhibited principle peaks at wave numbers of $3197.48 \mathrm{~cm}^{-1}$ (O-H Stretching), $2956.14 \mathrm{~cm}^{-1}$ (C-H Stretching), $1577.61 \mathrm{~cm}^{-1}(\mathrm{C}=\mathrm{N}$ Stretching), $1459.60 \mathrm{~cm}^{-1}$ (C=C Stretching) and 763.61 $\mathrm{cm}^{-1}$ (C-Cl Stretching). The spectra of Optimized LP5 tablet formulation exhibited all the principle peaks present in the Losartan Potassium pure drug. The results revealed that there were be no major interaction between drug and excipients used in the formulation of osmotic tablets. The IR spectra of pure drug and optimized formulation were shown in (Figure 8 and 9).

The DSC thermographic peaks for the pure drug Losartan potassium was observer at $274.6^{\circ} \mathrm{C}$, where as DSC thermographic peaks for the formulation blends was observed at 272. The results revealed that there was no interaction between drug and excipients used.(Figure 10-12).

The SEM photographs for the formulations LP5 and LP5C were taken to study the surface characteristics of the tablets. Smooth even surface was observed for the formulations LP5 and LP5C (with pore) before dissolution studies, where as pore enlargement and rough sur- 


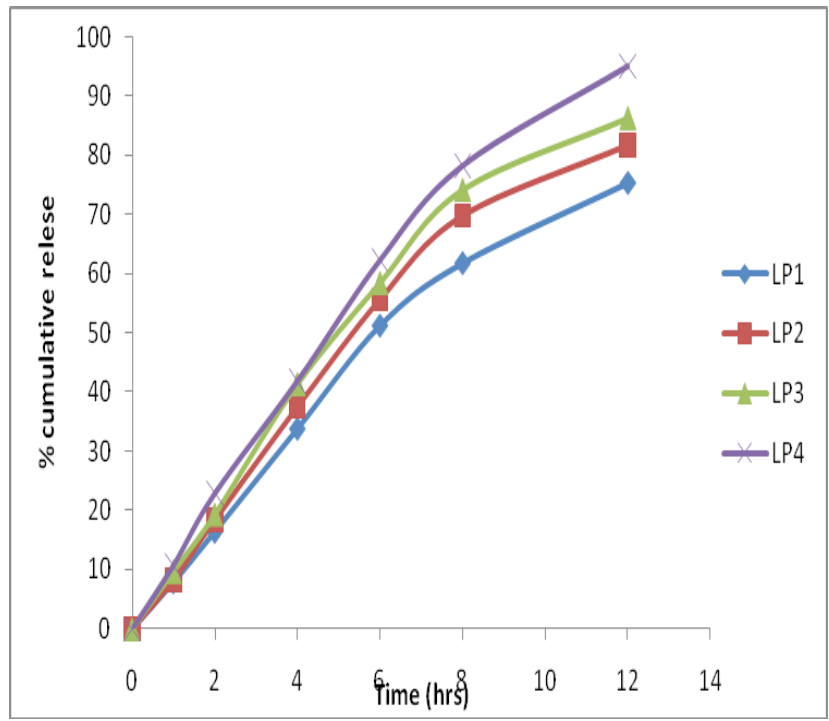

Figure 1: Dissolution Profiles for LP1 to LP4 Tablet Formulations

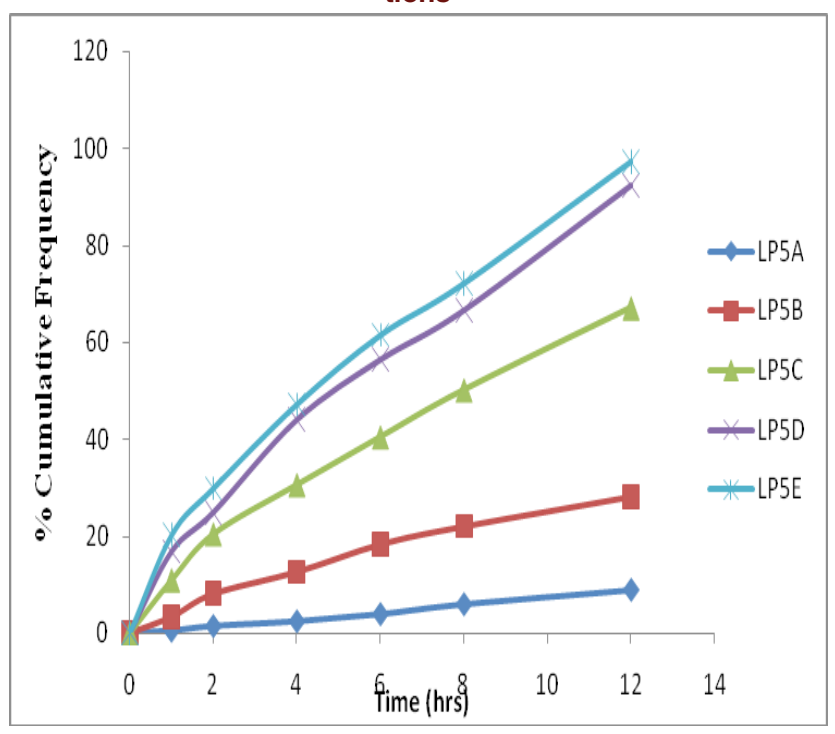

Figure 3: Dissolution profiles for LP5A to LP5E Tablet Formulations

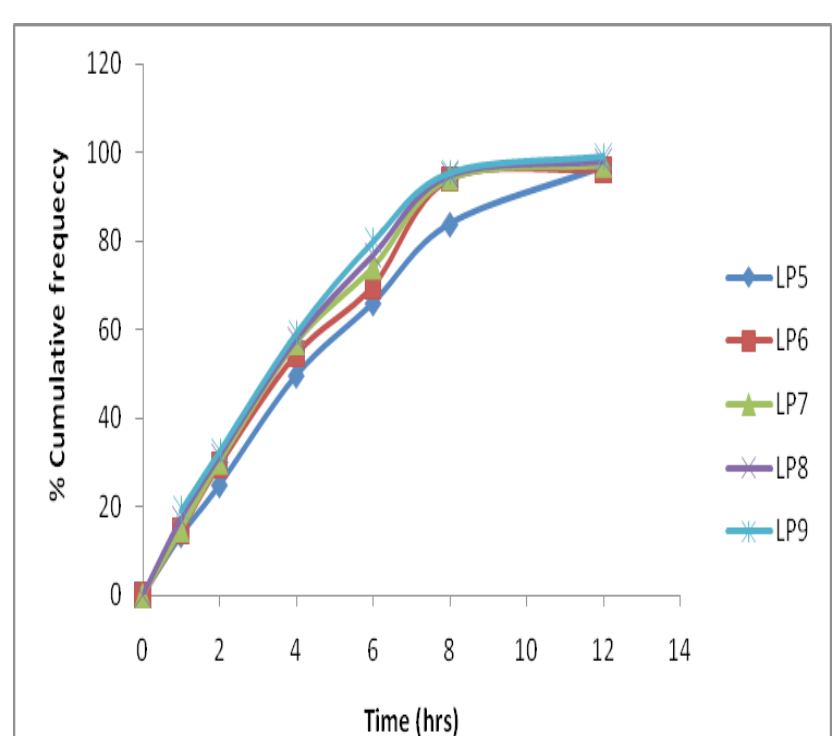

Figure 2: Dissolution profiles for LP5 to LP9 Tablet Formula-

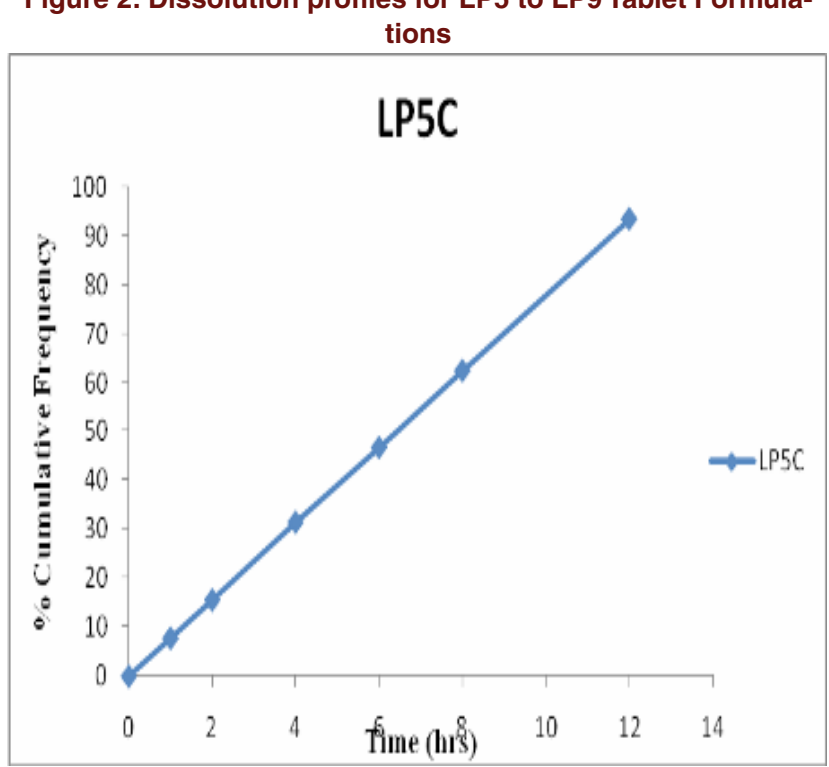

Figure 4: Dissolution profiles for LP5C Tablet Formulation with pore.

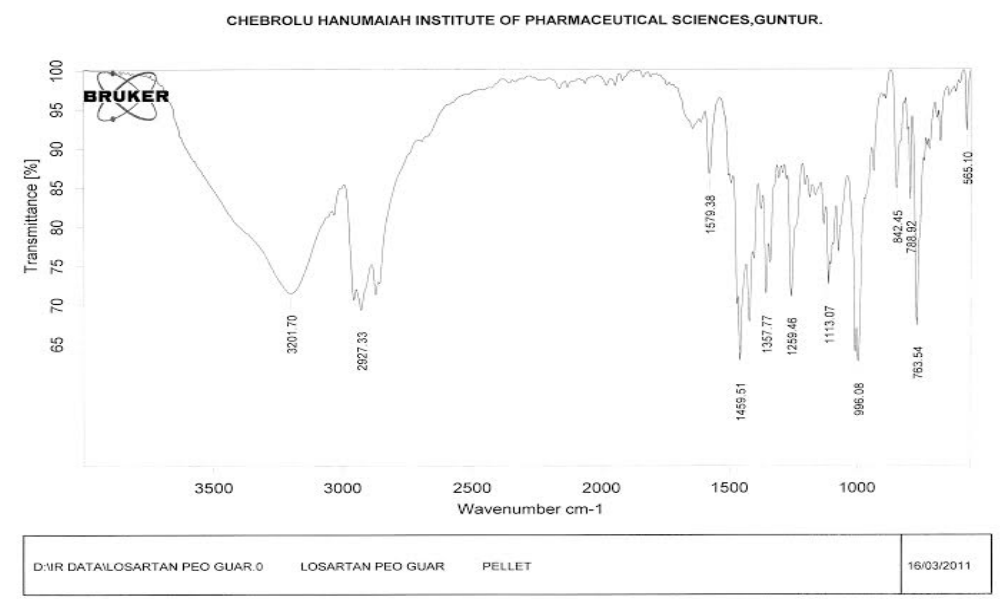

Figure 5: FTIR Spectra of Losartan Potassium 


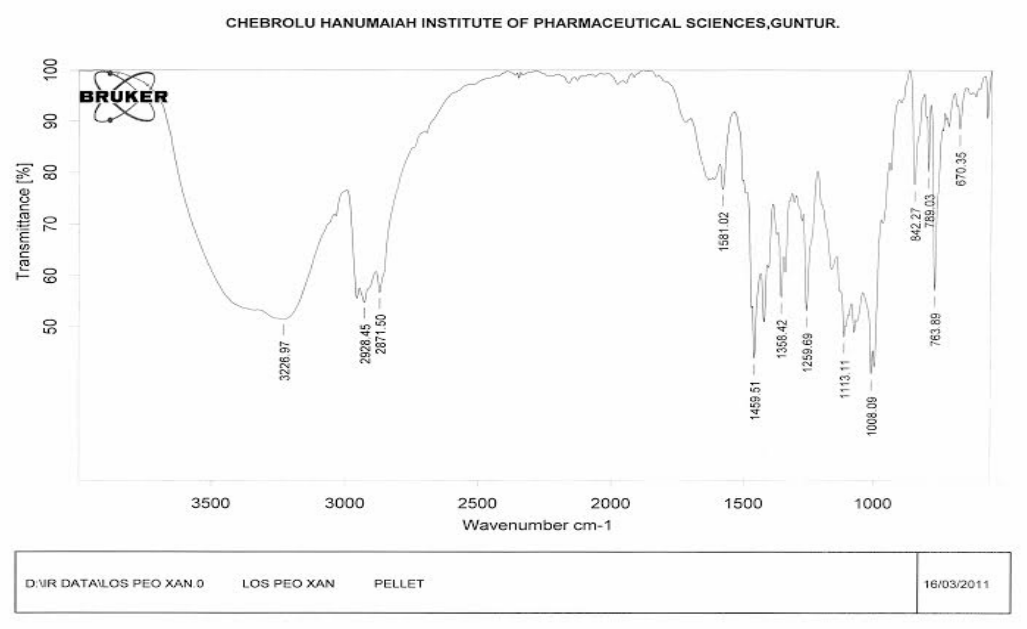

Figure 6: FTIR Spectra of Optimized LP5 Tablet Formulation.

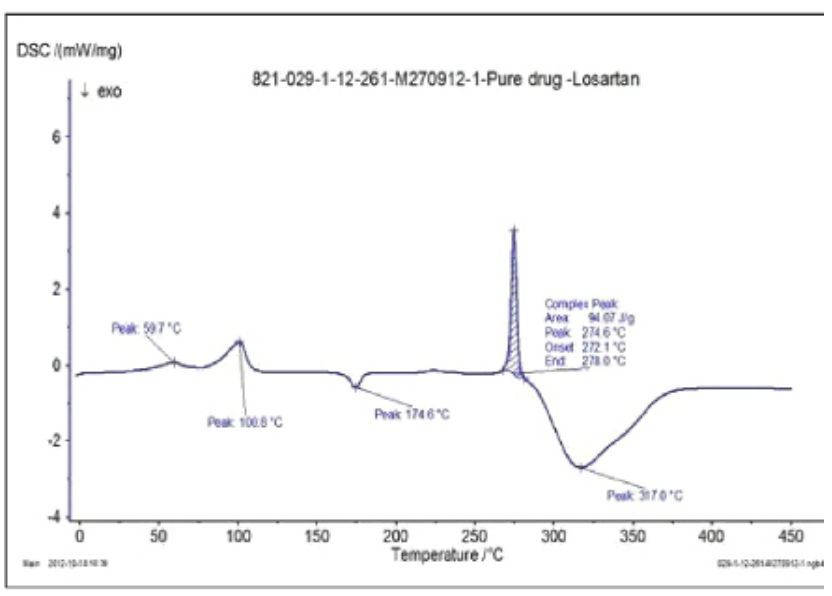

Figure 7: DSC Thermogram of Losartan Potassium

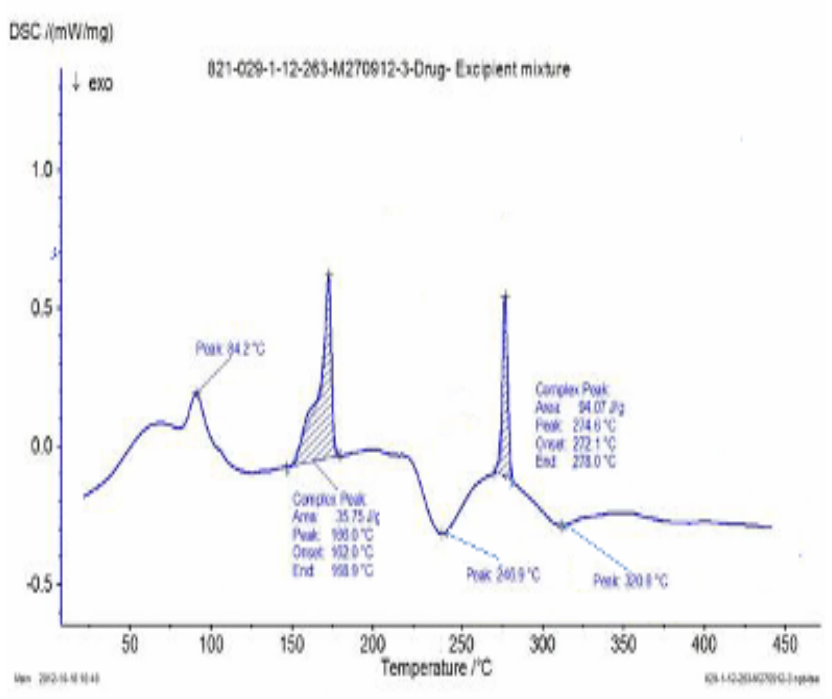

Figure 9: DSC Thermogram of LP5 Tablet Formulation.

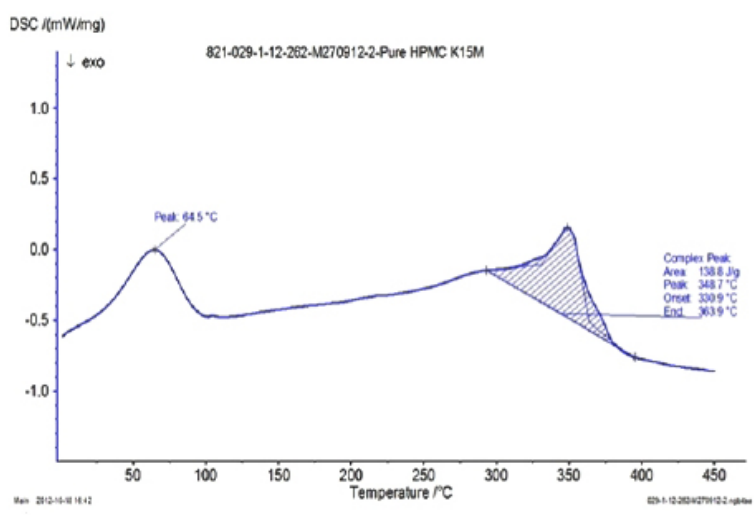

Figure 8: DSC Thermogram of HPMC K15M.

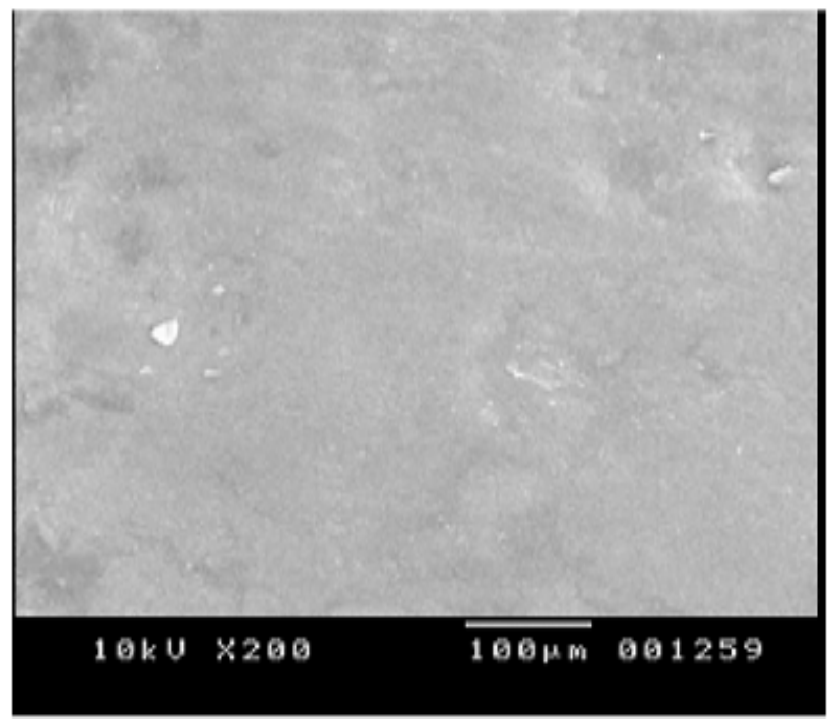

Figure 10: SEM Photograph of Coated LP5 Tablet Formulation without Pore. 


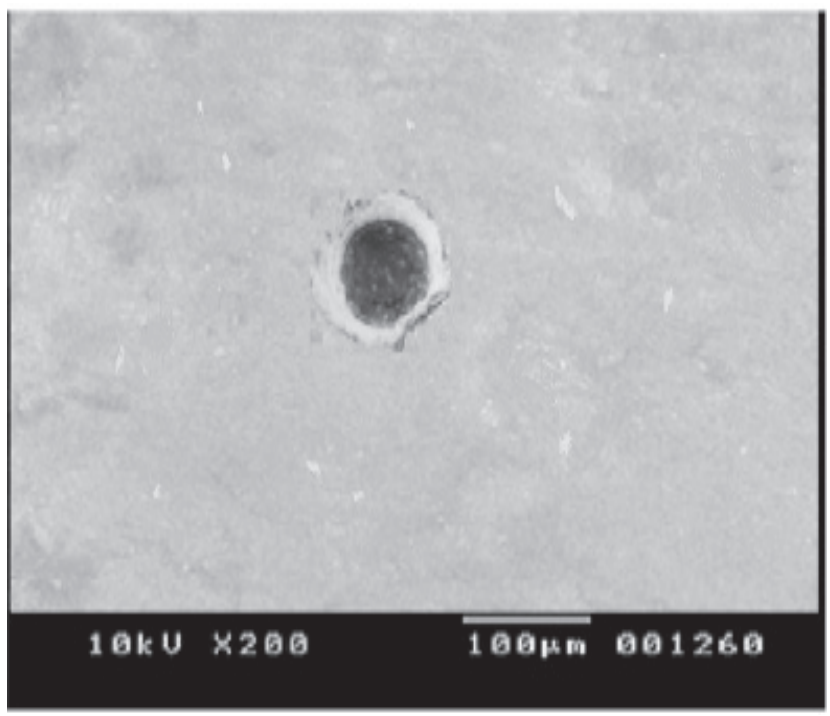

Figure 11: SEM Photograph of Coated LP5 Tablet Formulation with Pore before Dissolution

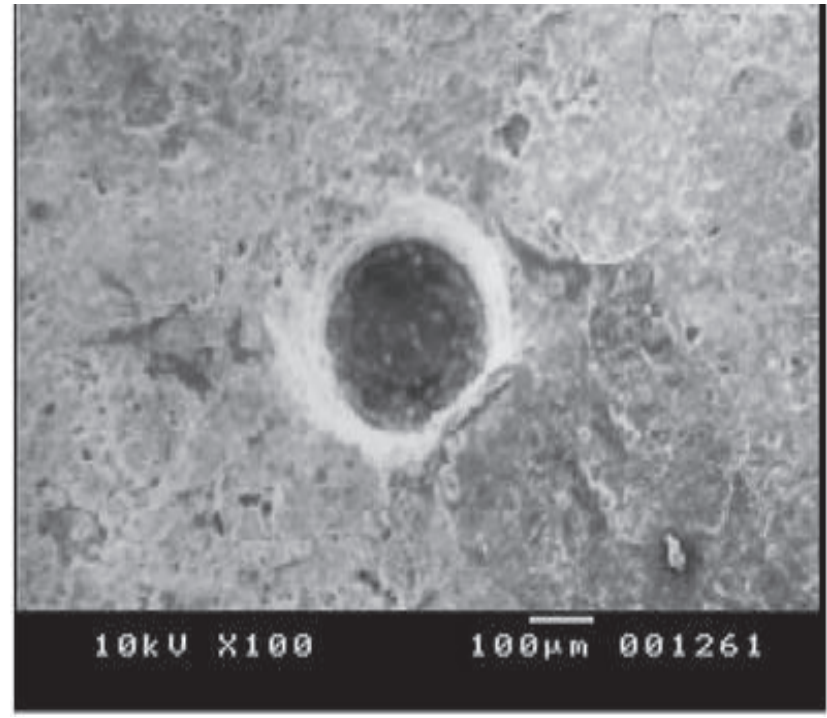

Figure 12: SEM Photograph of Coated LP5C Tablet Formulation with Pore after Dissolution.

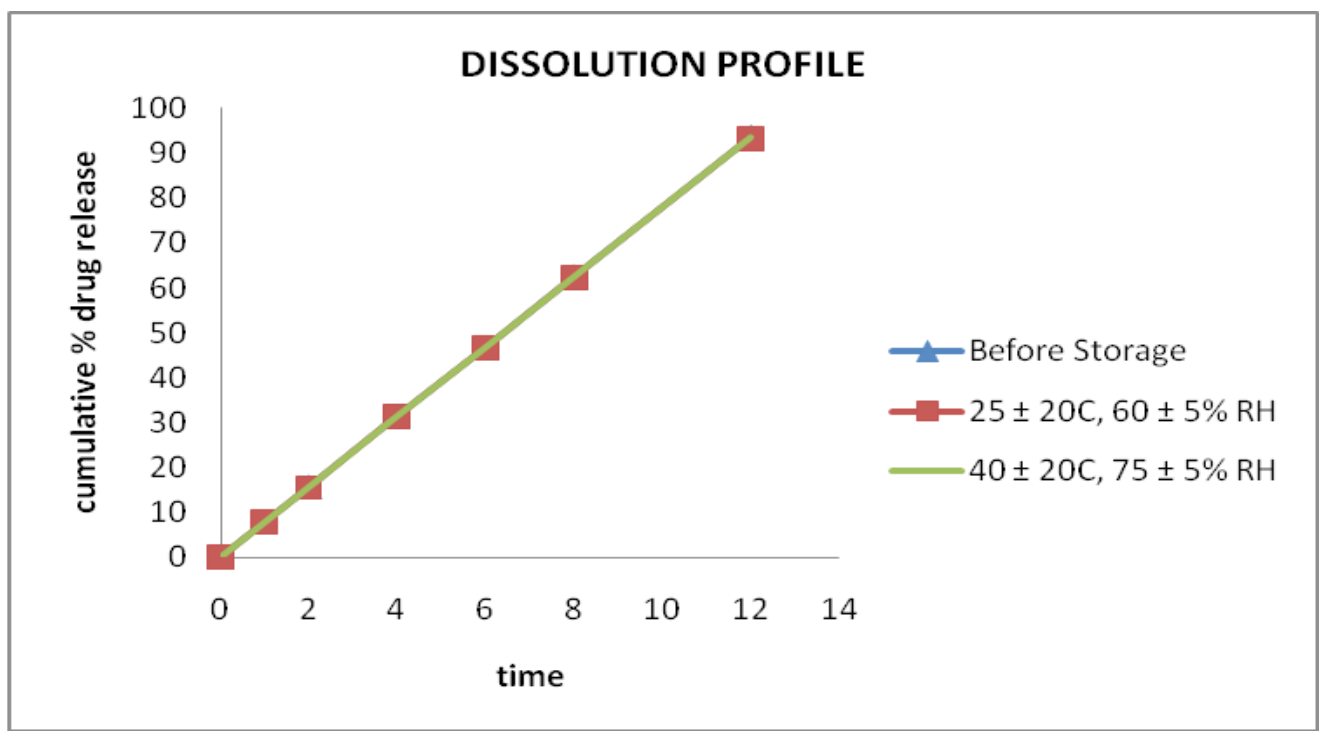

Figure 13: Release of Optimized LP5 Tablet Formulation before and After Storage at Different Conditions

face was observed in the formulation LP5C which may be due to the diffusion of drug through the pore.

Stability studies were conducted on selected formulations. Results indicated that there were no significant changes in physical parameters evaluated such as weight uniformity, hardness, friability and drug content. The physical parameters evaluated for optimised formulations were given in (Table 9). Drug release from the Osmotic tablets after storage at different conditions remained unaltered. The drug release profiles for the optimised formulation after storing at different storage conditions were shown in the (Figure 13). Thus the selected osmotic controlled release formulations were found to be quite stable.

\section{CONCLUSION}

The present study has shown that it is possible to extend the release of losartan potassium by formulating it as osmotic controlled release tablets employing HPMC K $15 \mathrm{M}$ as polymeric material and mannitol as osmogen. The formulation with micro-orifice after coating with ethylcellulose $7 \mathrm{cps}$ and PEG-4000 exhibited zero order drug release profile with constant release rate. 


\section{ACKNOWLEDGEMENTS}

The authors express their gratitude to $\mathrm{M} / \mathrm{S}$ AUROBINDO Pharma Ltd, Hyderabad and $\mathrm{M} / \mathrm{S}$ COLOREON ASIA Pvt Ltd, Mumbai for providing gift samples. The authors thankful to the management of Chebrolu Hanumaiah Institute of Pharmaceutical Sciences, Guntur for providing the facilities to carry out the research work.

\section{REFERENCES}

1. Thakor RS, Majmudar FD, Patel JK, Rajput GC. Osmotic Drug Delivery Systems Current Scenario. Journal of Pharmacy Research. 2010; 3(4): 771-5.

2. Panchaxari MD, Navik VK, Anand P, Vinayak SM, Mayank MS. Oral Osmotic Drug Delivery System: An Update. International Journal of Research and Pharmaceutical Sciences. 2011; 2: 225-36.

3. Gupta S, Ravindra PS, Rohitashva S, Renu K, Priyanka L. Osmotic Pumps: A Review. Int. J. Clin. Pharm. 2011; 2(6): 1-8.

4. Wakode R, Amrita B. Once a day osmotic drug delivery system for highly water soluble Pramipexole. J. Chem. Pharm. Res. 2010; 2(2): 136-46.

5. Theeuwes F, Swanson DR, Guittard F, Ayer F, Khanna S. Osmotic delivery systems for the 3-adrenoceptor antagonists metoprolol and oxprenolol: design and evaluation of systems for once-daily administration. B. J. Clin. Pharm. 1985; 19(2): 69-76.

6. Sean CS. The Complete Drug Reference, 34th Edition, London, England, UK: Pharmaceutical Press; 2011.

7. Hardy JG. Release rates from Sustained-Release buccal tablets in man. J. Pharm. Pharmacol. 1982; 34(S12): 91-5.

8. Hogan JE. Hydroxy propyl methyl cellulose sustained release technology. Drug. Dev. Ind. Pharm. 1989; 15(6-7): 975-99.

9. Shah AC. Gel-Matrix Systems Exhibiting Bimodal Controlled Release for Oral Delivery. J. Controlled. Release. 1989; 9(2) 169-75.

10. Wilson HC, Cuff GW. Sustained Release of Isomazole from Matrix Tablets Administered to Dogs. Journal of pharmaceutical Sciences. 1989; 78(7): 582-4.

11. Ozturk AG. Mechanism of Release from Pellets Coated with an Ethyl Cellulose-Based Film. J Controlled Release. 1990; 14(3): 203-13.

12. Narisawa S. Porosity-Controlled Ethyl Cellulose Film Coating. IV. Evaluation of Mechanical Strength of Porous Ethyl Cellulose Film. Chem. Pharm. Bull. 1994; 42(7): 1491-5.

13. Debord B. Study of Different Crystalline Forms of Mannitol: Comparative Behaviour under Compression. Drug. Dev. Ind. Pharm.1987; 13(9-11): 1533-46.

14. Molokhia AM. Aging of Tablets Prepared by Direct Compression of Bases with Different Moisture Content. Drug. Dev. Ind. Pharm. 1987; 13(9-11): 1933-46.

15. Leon L. The Theory and Practice of Industrial Pharmacy. Edition. 1990; -3: 314-5.

16. Herbert AL. Pharmaceutical Dosage Forms: Tablets. Informa health care. 2005; 2: 321-9.

17. Indian Pharmacopoeia. 2010; 2: 701. 